Kwartalnik Młodych Muzykologów UJ

nr 45 (2/2020), s. 109-126

DOI 10.4467/23537094KMMUJ.20.007.12534

www.ejournals.eu/kmmuj

\title{
Angelika Tracz
}

UNIWERSYTET WARSZAWSKI

\section{Płeć w muzyce tradycyjnej - przegląd nowych wyzwań badawczych etnomuzykologii polskiej XXI wieku}

\section{Abstract}

\section{Gender in Traditional Music: An Overview of the New Challenges Related to Polish Ethnomusicology in the 21st Century}

The subject of the article is to present the feminist trend in Western ethnomusicology and then to compare it with the state of research in Poland. The query included the latest Western musicological and ethnomusicological literature, as well as the known sources about gender in Polish traditional music. The author, based on the experience gained during the field research carried out in recent years, indicates possible changes in conducting and analysing the field in order to obtain more accurate knowledge about gender performativity in Polish folklore. 


\section{Keywords}

feminism, cricital theories, gender, ethnomusicology

Przemiany społeczne w sposób oczywisty implikują pewnego rodzaju zmiany w dyskursie naukowym. W XX wieku, na tle przemian kulturowo-społecznych, jako część teorii krytycznych wypracowywanych przez szkołę frankfurcką, w humanistyce zaczęto dostrzegać kwestię płci, seksualności i dyskryminacji z nimi związanej. Już w latach 60. jednym z tematów wykładów, seminariów i publikacji stała się reprezentacja kobiet i mniejszości jako przedmiotu i podmiotu badań naukowych. Obecnie, po wielu latach ewolucji zagadnień związanych z jej postrzeganiem, płeć społeczno-kulturową (gender) można zdefiniować jako formę reprezentacji złożonych relacji społecznych, a więc społeczny konstrukt, który umożliwia myślenie o współzależnościach między tożsamością seksualną a innymi zmiennymi: rasą, wiekiem, kulturą, klasą, stylem życia itd ${ }^{1}$. Wszystkie te zmienne są elementem tożsamości badanego podmiotu, osadzonego w materialnej rzeczywistości, naznaczonej relacjami władzy tożsamości badanego ${ }^{2}$. Zgodnie $\mathrm{z}$ tą definicją oraz poglądami przedstawicielki feminizmu drugiej fali, Simone de Beauvoir, „kobietą się nie rodzi, ale staje” ${ }^{3}$. Z kolei, dodając do tego teorię Judith Butler, owo „stawanie się" odbywa się za pomocą nieustannego odgrywania roli, która zostaje do nas przypisana i która wydaje się człowiekowi cechą wewnętrzną, niezmienną, tymczasem $\mathrm{w}$ wielu przypadkach jest wynikiem instytucjonalnego wywierania nacisku.

W tym miejscu nie sposób nie wspomnieć o błędnych interpretacjach tej definicji. Nie mówię tutaj o naukowej, konstruktywnej krytyce elementów teorii performatywności płci, którą podejmują m.in. Biddy Martin, Eve Sedgwick czy Slavoj Žižek ${ }^{5}$, a o jej obrazie w dyskursie

1 R. Braidotti, Podmioty nomadyczne. Ucieleśnienie i różnica seksualna w feminizmie wspótczesnym, tłum. A. Derra, Wydawnictwa Akademickie i Profesjonalne, Warszawa 2009, s. 138.

2 Tamże, s. 177.

3 S. de Beauvoir, Druga płeć, Wydawnictwo Literackie, Kraków 1972, s. 130-140.

4 J. Butler, Uwikłani w płeć. Feminizm i polityka tożsamości, Wydawnictwo Krytyki Politycznej, Warszawa 2008, s. 262.

5 Por. np. S. Žižek, The Ticklish Subject: The Absent Centre of Political Ontology, Verso, London-New York 2000. 
medialnym. Istnieją doniesienia nieodnoszące się do artykułów naukowych dotyczących stricte teorii gender, a jedynie jej krytyki ze strony środowisk konserwatywnych. Zarzuca się jej m.in. stronniczość, sprzeczność ze zdrowym rozsądkiem, rewolucyjność czy próbę inżynierii społecznej6. Tymczasem teoria płci społeczno-kulturowej nie polega na niczym więcej niż na próbie opisu problematyki różnorodności cech wrodzonych, przypisanych oraz nabytych człowieka oraz ich wpływu na jego życie. Co więcej, nie tylko nauki humanistyczne podejmują problematykę płci - o niejednoznaczności płci biologicznej i potrzebie jej dookreślenia wspomina się chociażby w naukach biologicznych ${ }^{7}$.

Choć zmagania muzykologii z materią feministyczną można datować na wczesne lata $80 .^{8}$, na większe opracowanie dotyczące płciowości sensu stricto musiała ona poczekać aż do roku 1991. Jedną z najważniejszych feministycznych badaczek muzyki jest Susan McClary. Zajmuje się ustalaniem, jak historycznie skonstruowane idee płci i seksualności wpłynęły na rozwój muzyki w czasach nowożytnych. W 1991 r. opublikowała pierwsze kompleksowe ujęcie tego tematu w książce Feminine Endings ${ }^{9}$. Dotyczy ona feministycznej krytyki muzyki w ramach tradycyjnych dyscyplin akademickich takich jak muzykologia czy teoria muzyki. McClary próbuje udowodnić, że w zależności od wybranego wątku niektóre elementy konstruktu płci kulturowych i ślady systemu patriarchalnego są obecne w źródłach dotyczących muzyki już od czasów starożytności.

W podobny sposób nurt feministyczny rozwijał się w etnomuzykologii. Wątek kobiecy obecny był w badaniach już za „panowania” muzykologii porównawczej, a więc na przełomie XIX i XX wieku. Bożena Muszkalska dokonała podsumowania działalności Richarda Wallaschka, w którego książce Primitive music: an inquiry into the origin and development of music, songs, instruments, dances, and pantomimes

6 Zob. także J.J. Pawłowicz, Ideologia gender realnym zagrożeniem dla małżeństwa i rodziny, „Teologia i moralność” 2012, nr 1, s. 139-154.

7 Zob. np. C. Ainsworth, Sex redefined, „Nature” 2015, nr 518, s. 288-291.

8 Zob. np. Women in Music: An Anthology of Source Readings from the Middle Ages to the Present, red. C. Neuls-Bates, Northeastern University Press, New York 1982.

9 S. McClary, Feminine Endings. Music, Gender, and Sexuality, University of Minnesota Press, Minneapolis 1991. 
of savage races ${ }^{10} \mathrm{znalazł}$ się specjalny fragment poświęcony kobietom ${ }^{11}$. Uznał on kobiety za uzdolnione bardziej od mężczyzn i przyznał, że przez względy społeczne, a więc rozwijający się system męskiej dominacji, nie były one w stanie rozwijać swojej muzycznej działalności ${ }^{12}$. Nawet jeśli jednak weźmiemy pod uwagę bardziej współczesnych badaczy/antropologów, to już John Blacking w swojej definicji muzyki, przedstawionej w How musical is man?, zawiera element krytyczny:

\begin{abstract}
Muzyka jest syntezą procesów kognitywnych, które są obecne w kulturze tworzonej przez człowieka: przyjmowane przez nią formy oraz wpływ, jaki ma na ludzi, są generowane przez doświadczenia społeczne istot ludzkich w różnych kulturowych przestrzeniach. Ponieważ muzykę tworzą dźwięki uporządkowane przez człowieka, uwidocznia ona spektrum doświadczeń jednostek w społeczeństwie ${ }^{13}$.
\end{abstract}

Na pierwszy rzut oka nie wydaje się, żeby poglądy Blackinga odnosiły się także do wykorzystania teorii płci kulturowej w etnomuzykologii. Jego definicja muzyki jest jednak bardzo szeroka. Po pierwsze, wspomina on o doświadczeniach istot ludzkich (mogących różnić się od siebie w sposób znaczący w zależności od tożsamości płciowej), a co za tym idzie - ich wpływie na kulturze tworzącą muzykę. Po drugie, muzyka ma uwidoczniać spektrum doświadczeń, zatem nie tylko doświadczeń dotyczących przeszłych i obecnych zdarzeń, ale także ich postrzegania, które w zależności od jednostki może być różne. Po trzecie w końcu, także inne prace Blackinga wskazują na jego zainteresowanie chociażby performatywnością zachowań muzycznych, a konkretniej - znaczenia cielesności w tym zachowaniu ${ }^{14}$. Słuszne wydaje się zatem twierdzenie, że tożsamość płciowa czy przynależność do płci kulturowej może mieć wpływ na wykonawstwo muzyki tradycyjnej czy muzykę tradycyjną jako taką.

10 R. Wallaschek, Primitive music: an inquiry into the origin and development of music, songs, instruments, dances, and pantomimes of savage races, Longmans, Green and C., London 1893.

11 B. Muszkalska, Biological and Social Aspects of the Theoretical Thought of Richard Wallaschek, [w:] Interdisciplinary Studies in Musicology, M. Jabłoński, R. Wieczorek (red.), Poznań 2009, s. 71-79.

12 Tamże, s. 78.

13 J. Blacking, How musical is man?, Faber \& Faber, Seattle 1973, s. 7-15.

14 J. Blacking, The Anthropology of the Body, Academic Press, London 1977. 
Prawdziwą pionierką okazała się jednak Ellen Koskoff. W swojej książce A Feminist Ethnomusicology: Writings on Music and Gender ${ }^{15}$ jako pierwsza etnomuzykolożka podsumowała ponad 50 lat studiów dotyczących płci w muzyce tradycyjnej, opisała je i scharakteryzowała problemy, które do naszych czasów pozostały nierozwiązane ${ }^{16}$. Przyjrzę się zatem wyróżnionym przez Koskoff trzem okresom historii zachodniej myśli feministycznej w etnomuzykologii, następnie jej współczesnym problemom, po czym spróbuję odnieść je do etnomuzykologii polskiej.

Pierwszym krokiem, podobnie jak w innych dziedzinach muzykologii, było zmierzenie się z problemem braku reprezentacji kobiet. Etnomuzykologia natrafiła na niego na początku lat 70. XX wieku z dwóch stron. Po pierwsze, uległa, jak zresztą większość nauk humanistycznych, implikowanej społeczno-politycznymi zmianami konstatacji dotyczącej wpływu patriarchatu na krytyczną ocenę twórców ${ }^{17}$. Jako odpowiedź na problem zaczęly pojawiać się publikacje „kompensujące” ów brak: opisywano praktykę muzyczną kobiet ${ }^{18}$, dokumentowano ich dotychczas pomijaną rolę w życiu muzycznym społeczności (jako przykład można tu podać jeden z pierwszych artykułów na ten temat, opisujący zachowania Maltanek, autorstwa Normy McLeod i Marcii Herdnon ${ }^{19}$ ), a co najważniejsze - $\mathrm{w}$ dyskursie naukowym ugruntował się pogląd, że w etnomuzykologii, podobnie jak chociażby w historii muzyki, faktycznie istnieje ogólny podział na dobrze opisaną twórczość i biogramy męskie oraz marginalizowaną sferę kobiecą. Równocześnie tendencje feminizujące pojawiły się dużo wcześniej również w naukach antropologicznych. Od początku XX wieku powoli rozwijał się nurt tzw. antropologii feministycznej, kontynuującej dzieło Ruth Benedict

15 E. Koskoff, A Feminist Ethnomusicology: Writings on Music and Gender, University of Illinois Press, Chicago 2014.

16 Znamienne jest, że autorką tego rodzaju opracowania jest kobieta. Tematem wartym analizy, ale nieujętym w niniejszym artykule jest pozycja kobiet-etnomuzykolożek w dyskursie naukowym: podejmowane przez nie kwestie, sposób przeprowadzania badań, ich efekty itd.

17 Zob. np. L. Nochlin, Why Have There Been No Great Woman Artists?, w: Woman in Sexist Society: Studies in Power and Powerlessness, red. V. Gornick, B. Moran, Basic Books, New York 1971.

18 Zob. np. B.W. Lee, Evolution of the Role and Status of Korean Professional Female Entertainers (Kisaeng), „World of Music” 1979, nr 21, s. 75-81.

19 M. Herdnon, N. McLeod, The Bormliza: Maltese Folksong Style and Women, „The Journal of American Folklore" 1975, nr 347, s. 81-10o. 
czy Zory Neale Hurston. I tu również pierwsze publikacje dotyczyły przywracania kobietom statusu odrębnych aktorek społecznych i kulturowych ${ }^{20}$. Na początku lat 8o. Elizabeth Wood wprowadziła do etnomuzykologicznego salonu rozróżnienie pomiędzy płcią biologiczną i kulturową, a następnie wskazała miejsca, gdzie gender studies okazują się niezbędne w badaniu muzyki tradycyjnej. Umiejscowiła również badania nad płcią w szerszym kontekście badań nad dyskryminacją ${ }^{21}$. Przez kilkanaście lat badaczki zachodnie zajmowały się zatem powiązaniami różnych osób, w tym kobiet, tak z muzyką, jak i z systemem (społecznym, religijnym), w którym ich muzyka funkcjonuje.

Kolejny etap wywołał w etnomuzykologii trzęsienie ziemi. Feminizm trzeciej fali początku lat 9o. niemal całkowicie zerwał z konceptem dającej się zdefiniować płci; poruszany był problem opresyjności języka i zachowań kulturowych, zestawiano feminizm z postkolonializmem, a co najważniejsze - pojawiały się pierwsze prace muzykologiczne dotyczące teorii queer ${ }^{22}$. W tym czasie co prawda powstały pierwsze encyklopedyczne wzmianki na temat kobiet w muzyce oraz książki - kamienie milowe nurtu feministycznego - $\mathrm{z}$ drugiej jednak strony etnomuzykolożki oraz antropolożki sygnalizowały, jak trudno jest przełożyć bardzo skomplikowane i zindywidualizowane zagadnienia dotyczące płci na rzeczywistość badań terenowych i ich opracowywa$n^{23}{ }^{23}$. Szczególnie ciekawą kwestią poruszaną w tym czasie była relacja osoby z instrumentem oraz styl gry, badany w zależności od czynników środowiskowych wpływających na wykonawcę. Paląca potrzeba podsumowania wszystkich tych zagadnien znalazła swoje spełnienie w publikacjach Music and Gender Study Group - działającego od 1985 roku zrzeszenia naukowców promujących zrównoważone pod względem płciowości podejście do badań działalności muzycznej i tanecznej. Jego postulaty obejmują: podejście krytyczne do ról płciowych prezentowanych w badaniach etnomuzykologicznych, zidentyfikowanie luk

20 Zob. np. P. Golde, Women in the Field: Anthropological Experiences, University of California Press, Los Angeles 1986; M.Z. Rosaldo, L. Lamphere, J. Bamberger, Woman, Culture, and Society, Stanford University Press, Stanford 1974.

21 E. Wood, Review Essay: Women in Music, „Signs” 1980, nr 6, s. 283-97.

22 S. Cusick, On a Lesbian Relationship with Music: A Serious Effort Not to Think Straight, w: Queering the Pitch: The New Gay and Lesbian Musicology, red. P. Brett, E. Wood, G.C. Thomas, Routledge, New York 1994, s. 67-83.

23 E. Koskoff, dz. cyt., s. 71-72. 
występujących w badaniach problematyki gender czy rozbudowywanie potrzebnej do tych badań terminologii ${ }^{24}$.

Do najważniejszych wniosków wypływających podczas spotkań Music and Gender Study Group odbywających się od 1985 r. i towarzyszących im publikacji należała przede wszystkim potrzeba rewizji spojrzenia badaczy na swoją pracę pod względem ulegania społecznym konstruktom, stereotypom i uprzedzeniom ${ }^{25}$. Podobna zmiana powinna dotknąć także historyczne źródła dotyczące tradycyjnej muzyki i tańca. Co więcej, najnowsze badania pokazują, jak bardzo interdyscyplinarne powinny być profesjonalne badania terenowe i ich analiza. Szczególnie w publikacjach Pirkko Moisali and Beverley Diamond, opartych na podstawie wieloletnich badań terenowych opartych o kontekst historyczny, pogłębione biografie badanych, szeroko nakreślony kontekst kulturowy oraz istniejącą literaturę, klarowne stają się kierunki i wskazówki badawcze dla etnomuzykologii gender w badaniu obcych kultur ${ }^{26}$. Pirkko Moisala odnosi się ona konkretnie do wspomnianego już przeze mnie konceptu performowania płci autorstwa Judith Butler. Okazuje się bowiem, że na płciowość występu ma wpływ wiele innych czynników, takich jak miejsce wykonania, sama tożsamość wykonawcy, sytuacja, okoliczności, a nawet publiczność, na co do tej pory nie zwracano zbytniej uwagi ${ }^{27}$. Dopiero przy szeroko zakrojonych badaniach interdyscyplinarnych okazuje się, jak ważny jest czynnik performowanej płci badanej osoby i jak płynnie może on się zmieniać, a także jak zmiany społeczne z początków nurtu feministycznego w etnomuzykologii inspiruje kolejne pokolenie zachodnich badaczek.

W polskiej muzykologii tematyka płci pojawia się z rzadka i fragmentarycznie. Dopiero od kilku lat dość regularnie pojawiają się pozycje związane z muzykowaniem kobiet (wspomnieć tu należy np. badania Anety Markuszewskiej, Magdaleny Walter-Mazur, Magdaleny

24 Informacje dostępne na stronie International Council for Traditional Music, http:// ictmusic.org/group/music-and-gender [dostęp z 30 maja 2020].

25 N. Ceribašić, Theory and Method of the Gender-Based Studies in Music, „International Review of the Aesthetics and Sociology of Music" 1996, t. 27, nr 2, s. 187-19o.

26 E. Koskoff, dz. cyt. s. 156-158.

27 Zob. np. Moisala P., Gender Performance in a Finnish Dance Music Restaurant: Reflections on a Multicultural Fieldwork Experiment, Reflections on a Multicultural Fieldwork Experiment, „Narodna Umjetnost” 2001, t. 38, nr 1.; P. Moisala, H. Järviluoma, A. Vilkko, Gender and Qualitative Methods, SAGE Publications Ltd, London 2003. 
Dziadek ${ }^{28}$ czy niedawno opublikowany tom Musicology Today ${ }^{29}$ poświęcony kompozytorkom). Danuta Gwizdalanka dość sprawnie rozprawiła się ze stereotypami dotyczącymi płci w swojej popularnonaukowej książce Muzyka i płećs ${ }^{30}$. Bardzo ciekawe wnioski dotyczące samego znaczenia słowa gender oraz wskazówki dotyczące badań tej kategorii wysunęła Karolina Kizińska ${ }^{31}$. Według autorki poszukując znaczenia działalności kobiety muzykującej należy odnieść się zarówno do samej wykonawczyni, jak i organizacji społecznej, w ramach której występuje. Okazuje się, że w polskiej etnomuzykologii pojawiają się opracowania poruszające problematykę płci w bardzo podobny sposób: w korelacji z płcią przedstawia się kontekst wykonawczy, analizę pieśni, nastrój, czy towarzyszące wykonaniu emocje, co umiejscawia muzyczny efekt (często skomplikowany) w złożonej sieci relacji istniejącej w danej społeczności ${ }^{32}$. Jednak jedynego polskiego badania dotyczącego określenia płci badanych w korelacji z repertuarem oraz przedstawienia go $\mathrm{w}$ formie danych statystycznych podjął się Piotr Dahlig ${ }^{33}$. Dane te zostały poddane krytycznej ocenie przez Teresę Nowak $^{34}$. Na 543 jego informatorów 284 osoby to wokaliści, natomiast 259 - instrumentaliści. U wokalistów 42 osoby to mężczyźni, a 242 - kobiety, natomiast wśród instrumentalistów znalazły się tylko 4 kobiety.

28 Zob. np. A. Markuszewska, Kompozytorki i patronki muzyki w XVII i XVIII wieku. Wybrane portrety, Muzeum Pałacu Króla Jana III w Wilanowie, Warszawa 2017; Walter-Mazur M., Figura i fraktem. Kultura muzyczna polskich benedyktynek w XVII i XVIII wieku, Wydawnictwo Poznańskiego Towarzystwa Przyjaciół Nauk, Poznań 2014; M. Dziadek, Utwory fortepianowe polskich kompozytorek do 1939 roku. Kontekst kulturowy, strategie wyboru gatunków i środków, w: J. Krassowski (red.), Muzyka fortepianowa XIII, Gdańsk 2004, s. 544-560.

29 S. Żerańska-Kominek (red.), Musicology Today: Women-Composers in Poland. Their stories, ideas, and Music, Warszawa 2020, $\mathrm{nr} 16$.

30 D. Gwizdalanka, Muzyka i płeć, PWM, Warszawa 2001.

31 K. Kizińska, Gender a kultury muzyczne - kulturoznawcze spojrzenie na badania etnomuzykologiczne i historyczne, „Przegląd kulturoznawczy” 2012, nr 4, s. 382-39o.

32 Zob. np. B. Muszkalska, Tradycyjna wielogłosowość wokalna w kulturach basenu Morza Śródziemnego, Wydawnictwo Naukowe UAM, Poznań 1999; M. MałaniczPrzybylska, Między dźwiękami skalnego Podhala. Współczesna góralszczyzna, Wydawnictwa Uniwersytetu Warszawskiego, Warszawa 2018.

33 P. Dahlig, Ludowa praktyka muzyczna w komentarzach i opiniach wykonawców $w$ Polsce, Instytut Sztuki PAN, Warszawa 1993, s. 8-9.

34 T. Nowak, Muzykantki w kulturze muzycznej wsi polskiej. Zarys problematyki, „Etnomuzykologia polska” 2016, nr 1, s. 44-48. 
W związku $\mathrm{z}$ brakiem informacji na temat zadawanych pytań dotyczących tożsamości płciowej badanych, przyjmuję, że jej określenie odbyło się na podstawie cech biologicznych widocznych na pierwszy rzut oka. Nie jest to jednak zarzut - publikacja pochodzi z początków trzeciej fali feminizmu, kiedy teorie performatywnej płci kulturowej dopiero pojawiały się w dyskursie naukowym. Patrząc na przedstawione wyżej dane, możemy ostrożnie przyjąć dwie tezy. Po pierwsze, mieliśmy do czynienia z podziałem: większość zgodna z podziałem ról płciowych i mniejszość, stanowiąca wyjątki od reguły, które występują rzadziej w przypadku kobiet. Po drugie: większość mężczyzn można zakwalifikować do dokonujących aktów performatywnych przynależnych do sfery kultury (muzykanctwo), a większość kobiet - dokonujących aktów performatywnych przynależnych do sfery natury (repertuar obrzędowy) ${ }^{35}$. Powyższe stwierdzenia Teresy Nowak zdaje się potwierdzać Anna Czekanowska, która łączyła wykonawstwo kobiet z jego określoną funkcją, konkretnym wydarzeniem, inscenizacją, spotkaniem, obrzędem ${ }^{36}$.

$\mathrm{Na}$ fali dokonujących się na przełomie millenium zmian społeczno-obyczajowych środowisko folklorystyczne zainteresowało się tematyką dyskryminacji i zaczęło dokonywać rewizji swojego spojrzenia na aktywność muzyczną muzykantów, dodając do nich również przestrzeń dla muzykantek. Ich aktywność jest zapisywana na nośnikach cyfrowych i prezentowana w przestrzeni internetowej, co pozwala ją z łatwością popularyzować wśród znaczącej grupy odbiorców. Okazuje się, że w XXI wieku kobiety coraz częściej grają na instrumentach, a starsze muzykantki zapraszane są na warsztaty w charakterze nauczycielek. Obserwuje się coraz większą aktywność kobiet w nowo tworzonych kapelach, a także w zespołach ludowych, zachęca się do gry także dziewczynki od najmłodszych lat.

Jeśli jednak chodzi o starsze pokolenia artystek, zwykle wymienia się kilka najbardziej znanych nazwisk uznanych muzykantek: Bogusławę Dziadońkę, legendarną prymistkę z Podhala, niedawno

35 Większy odsetek wokalistów męskich oznacza najprawdopodobniej śpiewaków pogrzebowych, których obecność w zestawieniu jest zrozumiała - obrzędy związane $z$ religią katolicką są oparte na zasadach patriarchatu, zatem „męskie”, wpisane do sfery kultury.

36 A. Czekanowska, Towards a Concept of Slavonic Women's Repertoire, w: Music, Gender, and Culture, red. M. Herndon, S. Ziegler, Wilhelmshaven, New York 199o, s. 57-70. 
zmarłą założycielkę Kapeli Kurasie - Albinę Kuraś - oraz „pierwszą harmonistkę w spodniach”, Wiesławę Gromadzką. W ich przypadku przede wszystkim umiejętności i wynikająca $\mathrm{z}$ nich popularność sprawiły, że ich działalność została udokumentowana. Sam fakt, że znamy jedynie kilka nazwisk, które pozornie wypełniają naszą lukę wśród wszystkich muzykantów, przypomina znaną mechanizmowi dyskryminacji praktykę tokenizmu ${ }^{37}$ - istnieje reguła (mężczyźni $=$ muzykanci) oraz wyjątki od reguły (kobiety postawione na równi z mężczyznami), które w pierwszej chwili pozwalają myśleć, że jedynie merytoryczna ocena umiejętności innych muzykantek sprawiła, że nie są one znane. Jednak sytuacja (wcale) nie przedstawia się tak prosto. Na wielość wątków związanych z tematyką kobiecą w polskiej muzyce tradycyjnej wskazują polscy badacze folkloru oraz wykonawcy muzyki folkowej, często także zajmujący się badaniami „u źródeł”. Z jednej strony niemal wszyscy dostrzegają nieodwracalną kulturową zmianę i wynikającą z niej potrzebę rewizji działalności kobiet w kulturze polskiej wsi, z drugiej jednak pojawiają się wątpliwości dotyczące np. granicy pomiędzy zakazem a praktycznymi aspektami życia na wsi czy ingerencji czynników zewnętrznych w tkankę wiejską i życie osobiste badanych ${ }^{38}$.

Jedno jest pewne - w etnomuzykologii polskiej stan badań uwzględniających w sposób szczególny płeć to w dużej mierze terra incognita opierająca się na wnioskach wysnuwanych przez badaczy „na marginesie”. Opóźnienie w stosunku do innych gałęzi muzykologii wydaje się jednak oczywiste, jeśli weźmiemy pod uwagę przedmiot badań etnomuzykologii. Należałoby się zgodzić z Koskoff, która podkreśla, jak czasochłonne i żmudne jest dogłębne poznawanie opisywanej kultury, co znacznie utrudnia szybkie wysnuwanie jednoznacznych wniosków, szczególnie tych dotyczących kwestii moralno-etycznych, na podstawie przeprowadzonych badań terenowych w obliczu galopującej zmiany społecznej XX i XXI wieku ${ }^{39}$. Najprościej mówiąc, możliwe powody nieobecności tematyki płci w etnomuzykologii polskiej podzielić

$37 \mathrm{Na}$ tej samej zasadzie działa dyskryminacja rasowa, zob. np. G. Mixon, „Good Negro - Bad Negro": The Dynamics of Race and Class in Atlanta During the Era of the 1906 Riot, „The Georgia Historical Quarterly” 1981, nr 3, s. 593-621.

38 H. Matuszewska, K. Trebunia Tutka, A. Bieńkowski, R. Mazur-Hanaj, T. Janas, Kobiety-muzykantki, „Pismo folkowe” 2013, nr 108, s. 4-17.

39 E. Koskoff, dz. cyt., s. 168. 
można na dwa rodzaje: związane $\mathrm{z}$ analizą badania terenowego oraz związane $\mathrm{z}$ badaniem terenowym.

Nie ulega wątpliwości, że każdy naukowiec powinien przynajmniej starać się być na bieżąco z przedmiotem badań. W przypadku etnomuzykologa chcącego się zająć tematyką feministyczną, jest on zobowiązany zapoznać się szczególnie uważnie z literaturą powstałą na gruncie innych gałęzi muzykologii obok prac etnomuzykologicznych. To jednak dopiero początek naukowych zmagań - należy wziąć pod uwagę, że rozwój feminizmu w ostatnich stu latach przyspieszył na tyle, że obecnie mamy do czynienia z końcem jego trzeciej fali. Każda społeczna zmiana rodzi rewizję pojęć: najpierw dzieje się to na gruncie humanistyki zachodniej, a dopiero później z jej wytworami zapoznają się, a następnie inspirują etnomuzykolodzy, którzy dodatkowo powinni skonfrontować literaturę z również rozwijającym się dyskursem antropologicznym. Okazuje się zatem, że temat tylko pozornie wydaje się wąski, i zajmowanie się feminizmem w etnomuzykologii wymaga bardzo regularnego weryfikowania zgromadzonych już informacji.

Prawdziwym wyzwaniem jednak, w obliczu ciągle aktualizowanego stanu badań, stają się badanie terenowe. Przyjrzyjmy się dla przykładu dokumentacji wywiadu. Ostatnią spopularyzowaną na obszarze kraju "metodologią" badań etnomuzykologicznych są wskazówki ${ }^{40}$ Jadwigi i Mariana Sobieskich, obejmujące doświadczenia sięgające lat 50. XX wieku [sic!]. W załączonym do instrukcji przykładowym protokole ${ }^{41}$ nie wskazano miejsca na określenie tożsamości płciowej badanego. Prace należące do nurtu feministycznego wskazują, że niewątpliwie ma ona znaczenie i z pewnością nie jest tak oczywista, jak wydawało się badaczom tamtego okresu. Efektem uświadamiania dokonywanego przez pionierów gender w etnomuzykologii jest wspomniane już poszerzenie zakresu badania terenowego o te wątki np. w pracach Marii Małanicz-Przybylskiej czy Bożeny Muszkalskiej. Innym elementem, na który również warto zwrócić uwagę, jest oczywiście określenie, czy wykonawca swoimi muzycznymi zachowaniami przynależy do tradycyjnie pojmowanego, określonego wzorca ( $w$ naszym przypadku będzie to ogólny podział na mężczyzn-instrumentalistów i kobiety-śpiewaczki), czy może się z niego wyłamuje i dlaczego. Nie można także pominąć

\footnotetext{
40 J., M. Sobiescy, Polska muzyka ludowa i jej problemy, PWM, Warszawa 1973, s $458-476$.

41 Tamże, s. 476.
} 
pytań o repertuar (pytanie może paść zarówno w stronę publiczności, jak i występującego) oraz o indywidualną jego ocenę - czy przeznaczony jest do wykonywania dla każdego, czy powinna go wykonywać osoba o określonych cechach płciowych? Pytanie o ocenę utworu lub całej twórczości może również wywołać u badanego spostrzeżenia dotyczące cech muzycznych, być może przypisanych według autora wypowiedzi do pewnych cech ludzkich lub płciowych. Szczególnie podczas rozmowy z osobą wyłamującą się ze schematu powinno się także mieć na uwadze społeczny odbiór tego zachowania. Bardzo dobrym przykładem uzyskanych odpowiedzi na tego typu pytania jest fragment wywiadu przeprowadzonego ze Stefanem Kołazińskim, skrzypkiem z kapeli Kołazińskich ze Zdunkowa, w której grał razem ze swoją córką, Wiesławą Gromadzkąa ${ }^{42}$. Ze stron Kołazińskiego pada tam np. sformułowanie: „wszyscy chcieli zobaczyć, jak panienka gra” oraz wymienione są najdalsze miejsca, w które zapraszano kapelę także dlatego, że gra w niej kobieta. Przykład ten pokazuje, jak kształtuje się reakcja na niecodzienny dla kultury okolic Zdunkowa akt performatywny dokonany przez Wiesławę Gromadzką. Widać zatem, że mimo odległej daty publikacji wywiadu tematyka gender obecna była wśród badaczy folkloru, choć zapewne w sposób niezamierzony.

Anachroniczny kwestionariusz nie jest jednak największym problemem. W mojej ocenie niezwykle ważna jest postawa samego badającego. Oczywiste jest, że przeprowadzanie badań wymaga dużego poziomu empatii, taktu i wyczucia. Jednak, jeśli chodzi o relacje międzyludzkie, kwestie osobiste, indywidualne rytuały czy ewentualne tabu, tym bardziej potrzebne jest zaufanie badanego oraz całej społeczności, a także niezwykle trudne do osiągnięcia wzajemne zrozumienie i szczerość. W bardzo wielu przypadkach pytanie o tożsamość, role płciowe, dyskryminację stanowi sferę prywatną, o której rozmawiać nie przystoi, a jeżeli już, to z kimś zaprzyjaźnionym, „swoim”. Podobnie jest z ujawnianiem tego typu historii - wielu badaczy mogłoby ryzykować zerwanie kontaktu ze społecznością, którą czynnie obserwują oraz brak możliwości rewizyty przez kolejną grupę badaczy. O potrzebnej

42 Archiwalne nagranie rozmowy ze Stefanem Kołazińskim, słynnym skrzypkiem ze Zdunkowa i jego córką Wiesławą Gromadzką z 1971 roku, wyemitowane na antenie Programu Drugiego Polskiego Radia w audycji „Źródła” przez Magdalenę Tejchmę, https://www.polskieradio.pl/8/478/Artykul/2283666,Kapela-Kolazinskich-zeZdunkowa [dostęp 11 stycznia 2020]. 
wrażliwości przy badaniach oraz późniejszej ich ewaluacji wspominają już Sobiescy ${ }^{43}$ i to na nią należy zwrócić szczególną uwagę.

Przeprowadzone badania mogą dać odpowiedź na szereg pytań, z których część postaram się przytoczyć. Czy w polskiej muzyce tradycyjnej faktycznie istniał niepisany podział natura-kultura, w którym osoby o określonej tożsamości płciowej stawały się częścią systemu aktów performatywnych? Nawet jeśli udzielimy na to pytanie odpowiedzi twierdzącej (a - jak udowodniłam wyżej - nie jest to oczywiste), wątpliwości zaczynają się mnożyć. Bo czy w XXI wieku, kiedy kontekst wykonawczy jest zupełnie inny, podział ten w muzyce tradycyjnej nadal istnieje? Czy przejście z jednej strony na drugą (albo odwrotnie - jej nieprzekraczanie) stanowiło część pragmatyki wiążącej się z różnymi predyspozycjami fizycznymi kobiet i mężczyzn, czy - biorąc pod uwagę spektrum płciowości - to wcale nie miałoby znaczenia, a prawdziwy problem tkwił w dyskryminacji osób próbujących wyłamać się ze schematów (wtedy mielibyśmy do czynienia z tabu)? Co sprawia, że tak się dzieje? Czy mamy faktycznie do czynienia z tabu i jego przełamaniem?

Przy moich poszukiwaniach wypłynął jeszcze jeden niezmiernie ciekawy wątek. $Z$ informacji uzyskanych od młodszego pokolenia folkorystów zajmujących się archiwum Piotra Gana wynika, że przynajmniej w promieniu 50-70 km od miejsca urodzenia Gromadzkiej na harmonii lub akordeonie $\mathrm{w}$ tym samym czasie grały także inne kobiety $^{44}$. Znane są ich nazwiska, część z nich jeszcze żyje. W innych archiwach nie ma informacji na temat tego typu znalezisk. $Z$ kolei podczas badań terenowych we wrześniu 2019 r. w Muszynie i okolicach osobiście udało mi się trafić na muzyczne ślady po utalentowanej muzykantce w okolicach Złockiego, grającej na instrumentach dętych w kapeli weselnej z kilkoma mężczyznami.

Dwa powyższe przykłady wskazują, jak palącą potrzebą jest obecnie regularne prowadzenie badań choćby zahaczających o tematykę obecności kobiet muzykujących. Po zbadaniu wielu innych regionów kraju mogłoby się okazać, że kobiety muzykujące wcale nie były spotykane tak rzadko, jak nam się obecnie wydaje i na co wskazują statystyki. Być może ich obecność związana jest z konkretnym regionem, a może nawet całym krajem. Nie jest także jasna kwestia ustalenia momentu, w którym kobiety wzięły do rąk instrumenty. Idąc krok dalej - jest mało

43 J., M. Sobiescy, dz. cyt., s. 467.

44 Informacje uzyskane dzięki uprzejmości p. Piotra Baczewskiego. 
prawdopodobne, ale nadal możliwe, że od zawsze w obrębie kilku wsi była muzykująca kobieta, grająca lepiej lub gorzej, zapamiętana albo zupełnie zapomniana, ale niegdyśs stanowiąca element lokalnej kultury. Podsumowując - w świetle obecnej wiedzy nie możemy stwierdzić, czy występowanie muzykantek to niewiele znaczące zjawisko, zawierające w sobie jedynie kilka imion i nazwisk, regionalny fenomen, czy też zapomniana przez naukowców część muzycznej tradycji.

Przedstawione przeze mnie pytania i hipotezy to jedynie początek listy nieporuszonych problemów związanych z płciowością. Na stale powiększającą się objętość tej listy mogą narzekać jednak nie tylko Polacy. Także w światowym dyskursie etnomuzykologicznym, nawet przy uwzględnieniu wymienionej przeze mnie na początku wywodu literatury, nadal stosunkowo niewiele miejsca poświęca się płci, często traktując temat jako przemijającą naukową modę. Już w latach 8o. XX wieku Bruno Nettl zauważył, że etnomuzykolodzy są na początku drogi, jeśli chodzi o odniesienie relacji między tożsamością płciową czy orientacją seksualną muzykującego do muzyki przez niego tworzonej lub wykonywanej ${ }^{45}$. W podobnym tonie dwadzieścia lat później wypowiedziały się Moisala Pirrko oraz Beverly Diamond: „włączenie płci jako istotnego aspektu wszystkich badań etnomuzykologicznych dalekie jest od urzeczywistnienia"46. Wydaje się, że po kolejnych dwudziestu latach znowu zrobiono zaledwie kilka nieśmiałych kroków ku zgłębieniu tematu.

45 B. Nettl, The Study of Ethnomusicology: Thirty-One Issues and Concepts, University of Illinois Press, Chicago 2005, s. 450-46o.

46 M. Pirrko, B. Diamond, Music and Gender, University of Illinois Press, Chicago 200o, s. 347. 


\section{Bibliografia}

\section{Opracowania}

Ainsworth C., Sex redefined, „Nature” 2015, nr 518.

de Beauvoir S., Druga płeć, Wydawnictwo Literackie, Kraków 1972.

Blacking J., How musical is man?, Faber \& Faber, Seattle 1973.

Blacking J., The Anthropology of the Body, Academic Press, London 1977.

Braidotti R., Podmioty nomadyczne. Ucieleśnienie i różnica seksualna $w$ feminizmie współczesnym, tłum. A. Derra, Wydawnictwa Akademickie i Profesjonalne, Warszawa 2009.

Butler J., Uwikłani w płeć. Feminizm i polityka tożsamości, Wydawnictwo Krytyki Politycznej, Warszawa 2008.

Ceribašić N., Theory and Method of the Gender-Based Studies in Music, "International Review of the Aesthetics and Sociology of Music" 1996, t. 27, $\mathrm{nr} 2$.

Cusick S., On a Lesbian Relationship with Music: A Serious Effort Not to Think Straight, w: Queering the Pitch: The New Gay and Lesbian Musicology, red. P. Brett, E. Wood, G.C. Thomas, Routledge, New York 1994.

Czekanowska A., Towards a Concept of Slavonic Women's Repertoire, w: Music, Gender, and Culture, red. M. Herndon, S. Ziegler, Wilhelmshaven, New York 1990.

Dahlig P., Ludowa praktyka muzyczna $w$ komentarzach $i$ opiniach wykonawców w Polsce, IS PAN, Pracownia Historii i Teorii Muzyki, Warszawa 1993.

Dziadek M., Utwory fortepianowe polskich kompozytorek do 1939 roku. Kontekst kulturowy, strategie wyboru gatunków i środków, w: J. Krassowski (red.), Muzyka fortepianowa XIII, Gdańsk 2004.

Golde P., Women in the Field: Anthropological Experiences, University of California Press, Los Angeles 1986.

Gwizdalanka D., Muzyka i płeć, PWM, Warszawa 2001.

Herdnon M., McLeod N., The Bormliza: Maltese Folksong Style and Women, „The Journal of American Folklore” 1975, nr 347.

Kizińska K., Gender a kultury muzyczne - kulturoznawcze spojrzenie na badania etnomuzykologiczne $i$ historyczne, „Przegląd kulturoznawczy" 2012, nr 4. 
Koskoff E., A Feminist Ethnomusicology: Writings on Music and Gender, University of Illinois Press, Chicago 2014.

Lee B.W., Evolution of the Role and Status of Korean Professional Female Entertainers (Kisaeng), „World of Music” 1979, nr 21.

Małanicz-Przybylska M., Między dźwiękami skalnego Podhala. Współczesna góralszczyzna, Wydawnictwa Uniwersytetu Warszawskiego, Warszawa 2018.

Markuszewska A., Kompozytorki i patronki muzyki w XVII i XVIII wie$k u$. Wybrane portrety, Muzeum Pałacu Króla Jana III w Wilanowie, Warszawa 2017.

Matuszewska H., Trebunia Tutka K., Bieńkowski A., Mazur-Hanaj R., Janas T., Kobiety-muzykantki, „Pismo folkowe” 2013, nr 108.

McClary S., Feminine Endings. Music, Gender, and Sexuality, University of Minnesota Press, Minneapolis 1991.

Mixon G., „Good Negro - Bad Negro”: The Dynamics of Race and Class in Atlanta During the Era of the 1906 Riot, „The Georgia Historical Quarterly" 1981, $\mathrm{nr} 3$.

Moisala P., Järviluoma H., Vilkko A., Gender and Qualitative Methods, SAGE Publications Ltd, London 2003.

Moisala P., Gender Performance in a Finnish Dance Music Restaurant: Reflections on a Multicultural Fieldwork Experiment, „Narodna Umjetnost" t. 38, $\mathrm{nr} 1$.

Moisala P., Diamond B., Music and Gender, University of Illinois Press, Chicago 2000.

Muszkalska B., Studia "gender" w (etno)muzykologii, w: O kulturze i jej poznawaniu: prace ofiarowane Profesorowi Stanisławowi Pietraszce, red. S. Bednarek, K. Łukasiewicz, Wydawnictwo i Drukarnia DTSK „Silesia”, Wrocław 2009.

Muszkalska B., Tradycyjna wielogłosowość wokalna w kulturach basenu Morza Śródziemnego, Wydawnictwo Naukowe UAM, Poznań 1999. Women in Music: An Anthology of Source Readings from the Middle Ages to the Present, red. C. Neuls-Bates, Northeastern University Press, New York 1982.

Nettl B., The Study of Ethnomusicology: Thirty-One Issues and Concepts, University of Illinois Press, Chicago 2005.

Nochlin L., Why Have There Been No Great Woman Artists?, w: Woman in Sexist Society: Studies in Power and Powerlessness, red. V. Gornick, B. Moran, Basic Books, New York 1971. 
Nowak T., Muzykantki w kulturze muzycznej wsi polskiej. Zarys problematyki, „Etnomuzykologia polska” 2016, nr 1.

Pawłowicz J.J., Ideologia gender realnym zagrożeniem dla małżeństwa i rodziny, „Teologia i moralność” 2012, nr 1, s. 139-154.

Rosaldo M.Z., Lamphere L., Bamberger J., Woman, Culture, and Society, Stanford University Press, Stanford 1974.

Sobiescy J., M., Polska muzyka ludowa i jej problemy, PWM, Warszawa 1973.

Wallaschek R., Primitive music: an inquiry into the origin and development of music, songs, instruments, dances, and pantomimes of savage races, Longmans, Green and C., London 1893.

Walter-Mazur M., Figura i fraktem. Kultura muzyczna polskich benedyktynek w XVII i XVIII wieku, Wydawnictwo Poznańskiego Towarzystwa Przyjaciół Nauk, Poznań 2014.

Wood E., Review Essay: Women in Music, „Signs” 1980, nr 6.

Žižek S., The Ticklish Subject: The Absent Centre of Political Ontology, Verso, London-New York 2000.

Żerańska-Kominek S. (red.), Musicology Today: Women-Composers in Poland. Their stories, ideas, and Music, Warszawa 2020, nr 16. 